\title{
Manifeste contre les attaques infligées aux droits des autochtones du Brésil
}

Simone Dreyfus, Jonathan D. Hill et Lia Zanotta Machado

\section{Q OpenEdition}

\section{Journals}

Édition électronique

URL : https://journals.openedition.org/jsa/14918

DOI : 10.4000/jsa. 14918

ISSN : 1957-7842

Éditeur

Société des américanistes

Édition imprimée

Date de publication : 15 juin 2017

ISSN : 0037-9174

\section{Référence électronique}

Simone Dreyfus, Jonathan D. Hill et Lia Zanotta Machado, « Manifeste contre les attaques infligées aux droits des autochtones du Brésil », Journal de la Société des américanistes [En ligne], 103-1 | 2017, mis en ligne le 01 juin 2017, consulté le 04 septembre 2022. URL : http://journals.openedition.org/jsa/ 14918 ; DOl : https://doi.org/10.4000/jsa.14918 


\title{
Manifeste contre les attaques infligées aux droits des autochtones du Brésil
}

\author{
Simone Dreyfus, Jonathan D. Hill \\ et Lia Zanotta Machado *
}

Mai 2017

Nous, professeurs, intellectuels et universitaires, manifestons avec véhémence notre refus de la politique anti-autochtone de l'État brésilien et notre préoccupation vis-à-vis d'une politique qui a déjà des conséquences génocidaires dans les États du Mato Grosso do Sul, de Bahia et du Maranhão. Ces cinq dernières années, les attaques contre les droits autochtones se sont aggravées et ont permis leur révision en autorisant la contestation légale des droits acquis. Les droits constitutionnels garantis aux populations autochtones sont pris en otage par la situation politique du pays et soumis à des amendements de la Constitution votés et approuvés par le Congrès national. Cette attaque de la Constitution est conduite principalement par ce qu'on appelle le « lobby de l'agrobusiness » (bancada ruralista). Les attaques sur le plan judiciaire ont augmenté à partir de l'imposition de dix-neuf conditions pour la démarcation d'une terre autochtone particulière, la T.I. Raposa Serra do Sol (qui fit l'objet d'une bataille juridique). Ces dix-neuf conditions ont été établies par la Cour suprême (Supremo Tribunal Federal) en octobre 2013, faisant alors jurisprudence. De ces dispositions ont découlé de nouveaux concepts juridiques, non prévus par la Constitution, qui orientent d'un côté le discours anti-autochtone, et de l'autre, de façon encore plus nocive, les verdicts des tribunaux concernant les terres autochtones.

Le plus important de ces nouveaux concepts est celui de « marque temporelle » (marco temporal) qui soutient que les Indiens n'auraient droit qu'aux terres autochtones effectivement occupées le 5 octobre 1988, date de promulgation de la Constitution. Même si la session plénière de la Cour suprême avait décidé que les conditions de Raposa Serra do Sol n'étaient pas valables pour d'autres démarcations judiciaires, cette thèse a permis au tribunal d'annuler postérieurement les démarcations de terres autochtones Guarani, Kaiowá et Canela situées au Mato Grosso do Sul et au Maranhão et, plus grave encore,

* S. Dreyfus, Président, Groupe international de travail pour les peuples autochtones (GITPA); J. D. Hill, President, Society for the Anthropology of Lowland South America (SALSA); L. Zanotta Machado, Presidente, Associação Brasileira de Antropologia (ABA). 
celle de la terre autochtone Terena Limão Verde, également au Mato Grosso do Sul, démarquée et homologuée depuis plus de dix ans. Sur le plan législatif, les actions contre les droits constitutionnels des autochtones commencèrent peu après la promulgation de la Constitution. Le droit à la terre étant toujours visé, comme le montre la proposition d'amendement à la Constitution $\mathrm{n}^{\circ} 215$ (PEC 215) dont l'objectif est de transférer au Congrès national les processus de démarcation des terres autochtones et de rendre possible l'annulation de démarcations déjà homologuées.

L'attaque la plus récente de l'Assemblée législative a été la création d'une Commission d'enquête parlementaire destinée à enquêter sur les organes fédéraux chargés de la politique foncière des autochtones et d'autres populations traditionnelles (quilombolas), la Fondation nationale de l'Indien (FUNAI), l'Institut national de colonisation et de réforme agraire (INCRA). Le but est de déstabiliser le processus de démarcation, ainsi que certaines des principales institutions non gouvernementales qui appuient les luttes autochtones (Conselho Indigenista Missionário [CIMI], Instituto Socioambiental [ISA], Centro de Trabalho Indigenista [CTI] et jusqu'à l'Associação Brasileira de Antropologia [ABA]). Sont aussi visés des anthropologues directement impliqués dans ces processus. Le rapport final de cette commission, qui risque d'être approuvé lundi (8 mai 2017), propose la mise en examen en masse de leaders autochtones, anthropologues, indigénistes, religieux et de plusieurs procureurs de la République. La plupart des inculpés n'ont même pas été entendus par la commission, n'ayant donc pas eu droit de se défendre. Avec l'actuel gouvernement fédéral, l'attaque envers les droits autochtones est devenue politique d'État, dès que le lobby de l'agrobusiness s'est trouvé installé au ministère de la Justice en la personne du rapporteur de la proposition d'amendement 215, le député Osmar Serraglio. Telle est la situation actuelle qu'affrontent les peuples autochtones au Brésil, créant une grande insécurité juridique et une augmentation exponentielle de la violence et légitimant des actions comme l'attaque brutale subie par les Gamela du Maranhão, il y a quelques jours. Il s'agit d'un cas de plus dans l'ensemble des violences infligées aux peuples autochtones qui se traduisent, entre autres choses, par la criminalisation croissante des leaders autochtones et par des déplacements forcés de populations, les obligeant à migrer vers les périphéries des villes et les « favelas » (bidonvilles) et posant des problèmes de santé collective, d'insécurité alimentaire, de crimes, d'alcoolisme et de suicides.

En conséquence, nous demandons à l'État brésilien de respecter les droits constitutionnels des peuples autochtones ainsi que les traités internationaux qui protègent les populations traditionnelles. Nous savons tous que ces terres sont indispensables à leur survie ainsi qu'à la diversité de la vie de notre planète. 